\title{
TO DETERMINE THE FREQUENCY OF PROSTATE MALIGNANCY IN PATIENTS WITH CLINICALLY BENIGN PROSTATE.
}

\author{
1. FCPS Urology \\ Registrar / Consultant \\ Department of Urology \\ Peoples University of Medical and \\ Health Sciences for Women/ \\ Hospital Nawabshah, SBA. \\ 2. FCPS, MS Urology \\ Head of Department \\ Department of Urology \\ Peoples University of Medical and \\ Health Sciences for Women/ \\ Hospital Nawabshah, SBA. \\ 3. MS General Surgery \\ MS (Urology) \\ Assistant Professor \\ Anatomy Department \\ Peoples University of Medical and \\ Health Sciences for Women \\ Nawabshah, SBA. \\ 4. MS Urology \\ Assistant Professor \\ Department of Urology \\ Peoples University of Medical and \\ Health Sciences for Women, \\ Nawabshah, SBA. \\ Correspondence Address: \\ Dr. Salman Manzoor Qureshi \\ H No 154/B, Block E, Unit \# 6 . \\ Latifabad, Hyderabad. \\ salman_capricorne@yahoo.com \\ drsalman340@gmail.com
}

Article received on:

21/06/2018

Accepted for publication:

$15 / 12 / 2018$

Received after proof reading:

$31 / 07 / 2019$

\section{INTRODUCTION}

Worldwide one of the most common malignancies in men is the Prostate cancer (CaP). ${ }^{1}$ The most common problem encountered in the management of this disease is a delayed presentation which causes tumour treatment to a stage where it is incurable. No identifiable cause has been found yet except genetic tendency, smoking and increased dietary fat. ${ }^{2}$

Urinary tract symptoms mostly occur due to enlarging prostate in the ageing male. A possible link between lower urinary tract symptoms,

\begin{abstract}
Salman Manzoor Qureshi ${ }^{1}$, Muhammad Ali Sohail ${ }^{2}$, Mujeeb ur Rehman Sahito ${ }^{3}$, Aijaz Hussain Memon $^{4}$ ABSTRACT... To see the frequency of prostatic malignancy in patients presenting with clinically Peoples University of Medical and Health Sciences for Women / Hospital Nawabshah. Period: Fifteen Months, From October 2016 to December 2017. Materials and Methods: A total of 100 patients who presented with the clinically benign prostate in Urology OPD were enrolled. investigation includes complete blood count, urea, creatinine, random blood sugar (RBS), urine DR and CS, coagulation profile were performed before TURPTURP performed under spinal $7.19 \mathrm{yrs}$. Most of the patients with (IPSS 20-35) BPH have lower urinary tract symptoms (both obstructive and irritative). DRE was done in all patients to estimate the size of the prostrate, it was varying from grade 1 enlarged $n=27(27 \%)$, grade 2 enlarged $n=36(36 \%)$, to grade 3 enlarged in $n=37(37 \%)$. There were $3(3 \%)$ cases reported to have prostate cancer, with findings no correlation. Conclusion: BPH is more common between 60-80yrs. When patient undergo TURP or open prostatectomy, every specimen should be sent for biopsy because prostate cancer is only confirmed by biopsy, so that prostate cancer is detected early Radiology \& PSA morbid condition, so effective measures should be taken to detect prostatic cancer, so that patient can be properly treated according to the stage.
\end{abstract}

Key words: Benign Prostate Hyperplasia (BPH), Digital Rectal Examination (DRE), Prostate Cancer (CaP), Prostate Specific Antigen (PSA), Transrectal ultrasound (TURS), prostate malignancy in patients with clinically benign prostate. Professional Med J 2019; 26(8):1289-1295. DOI: 10.29309/TPMJ/2019.26.08.3871 
are being used to detect malignancy early. The widely used protocol is the use of DRE (digital rectal examination) together with transrectal ultrasonography (TRUS) and serum prostatic specific antigen (PSA). Usually asymptomatic patients when diagnosed, frequently the diagnosis is by abnormal DRE, increased PSA and abnormal findings on histopathology of TURP specimen. The abnormal findings in DRE which favour's towards malignancy include hard consistency, palpable nodule, obliterated median sulcus, asymmetry, or induration. DRE can detect tumour in the posterior and lateral aspects of the prostate gland; an inherent limitation to the digital examination is that only $85 \%$ of cancers arise peripherally where they can be detected with a finger examination. ${ }^{7}$

Gray-scale TRUS has become the most common imaging modality for the prostate. Most commonly used for prostate cancer detection and also be used in the evaluation of other conditions such as infertility, TRUS technology has become a mainstay of many image-guided prostate interventions, including prostate biopsy, brachytherapy, cryotherapy, and high-intensity focused ultrasonography (HIFU), as well as being used in the evaluation of appropriate patients for treatment of benign prostatic hyperplasia $(\mathrm{BPH}) .^{8}$

In most of the cases when old age patient came to doctor with complaints of Lower urinary tract symptoms, are being initially treated as the benign disease of prostate like Benign prostatic enlargement and they initially got conservative treatment till the failure of conservative treatment or referred to through and comprehensive history, Examination and assessment by Proper Urologist. Sometimes prostatic carcinoma easily diagnosed initially on DRE, TRUS, PSA \& BIOPSY basis on initial workup, but sometime when these tools (other than biopsy) not guided the urologist toward Cap and patient underwent TURP for benign disease, then biopsy specimen told us about adenocarcinoma, proves too late for those not having a benign origin from very beginning. Therefore, it is of paramount importance to proceed with its accurate and early diagnosis so as to proceed with the appropriate course of action.

The purpose of this study was to determine the frequency of abnormal histopathology findings that favour the malignancy in clinically benign prostatic enlargement patients who underwent TURP.

\section{MATERIAL AND METHOD}

\section{Data Collection Procedure}

A total of 100 patients who presented with the clinically benign prostate in OPD at Department of Urology at Peoples University of Medical \& Health Sciences / Hospital, Nawabshah were enrolled

After informed consent, and the full explanation of the study their data was taken and then entered into the Performa. All concern data regarding Age, mode of presentation (lower urinary tract symptoms with IPSS score/ Acute retention of urine), comorbid, clinical examination findings, pre voided and post-void residual urine determination (on ultrasonography) were entered. The inclusion criteria were refractory retention of urine, moderate to severe score in IPSS, No bony pain or a backache, with no weight loss, no sign of malignancy on digital rectal examination, post residual urine more than $100 \mathrm{ml}$. DRE was done in all patients, the size of the prostate was varying from grade 1 to grade 4 enlargements according to modified Romero grading by Lodh $B$ et al. ${ }^{9}$ According to this classification, grade 1 enlargement (easy access to upper limit of prostate), grade 2 enlargement (lateral margin palpable but upper margin was palpated with some difficulty), grade 3 enlargement (upper margin was palpated with marked difficulty) Grade 4 as inability to access the upper limit even with effort, deep depth lateral sulcus ( $>$ two finger width), obliteration of median sulcus with rounded posterior surface.

The laboratory investigation includes complete blood count, urea, creatinine, random blood sugar (RBS), urine DR and CS, coagulation profile were performed before TURP. TURP performed under spinal anesthesia. After TURP the prostatic tissue chips were sent for histopathology as a routine. 


\section{Data Analysis Procedure}

All data was entered in statistical package for social Sciences (SPSS) 20.0 version.

\section{Ethical Consideration}

Informed consent was taken from the patients at the time of Admission; Confidentiality about their particulars was kept secret, no any force used to enroll the patient in the study to participate.

\section{RESULTS}

Out of 100 patients enrolled, the average age of the males was $71.38 \pm 7.19$ years. Among them, 65 males were between $60-70$ years old $(65 \%)$, while the others 21 males had age between 71$80 y$ rs $(21 \%)$ and the remaining 14 males were greater than 80 years (14\%).

Majority of the patients about $58 \%(n=58)$ with clinically benign prostatic enlargement were presented with lower urinary tract symptoms (LUTS). On detail evaluation of LUTS, we found to have increased frequency of maturation in $65 \%$ of patients, urgency $52 \%$, nocturia $70 \%$, straining $64 \%$, weak stream $56 \%$, intermittency $44 \%$, incomplete emptying $39 \%$. There were more than 4 symptoms in all the patients.

The other presentation was retention (refractory) of urine and was present in $37 \%$ of patients $(n=37)$. Among the remaining 5 patients, 3 patients presented with LUTS and hematuria ( $3 \%$, $n=3)$, and the last 2 patients $(2 \%, n=2)$ presented with LUTS and inguinal swelling.

All patients who presented with LUTS, their IPSS score were evaluated and we have found score between 20 and 35 in all patients with an enlarged prostate. In 39 patients the IPSS score was 20$25 / 35$, in 16 patients IPSS score was between 26$30 / 35$ and in remaining 8 patients the IPSS score was between 31-35 points.

DRE was done in all patients, the size of the prostate was varying from grade 1 to grade 3 enlargements according to Lodh $\mathrm{B}$ et $\mathrm{al}^{9}$ grading system. We found Grade 1 enlargement in 27 patients $(27 \%)$, grade 2 enlargement in 36 patients (36\%), and grade 3 enlargement in 37 patients (37\%). On DRE firm consistency was found and no nodule was palpable in all the patients. The median groove was palpable and freely mobile rectal mucosa over the prostate, and bulbocavernous reflex was positive.

The post-void residual volume estimation was done by ultrasonography of bladder revealed more than $100 \mathrm{ml}$ in $39 \%$ of patients. All patients present with normal renal functions.

Out of 100 patients, only 3 patient's biopsy report shows prostatic cancer. These cases of carcinoma were screened by prostate-specific antigen which was done after 1 month of TURP to exclude false elevation by instrumentation and TURP, and it was found to be elevated and it was between 4-10ng/ $\mathrm{ml}$. The mean age among patients with prostate malignancy was $69.67 \pm 3.05$ years, while the mean age among patients with clinically BPH was $71.43 \pm 7.28$ years. The age range, when compared with patients with BPH and Prostate carcinoma, revealed statistically non-significant value $p-0.720$. The DRE findings of both $B P H$ and Prostate carcinoma revealed non-significant value 0.437 .

On detail evaluation of biopsy report, the Gleason score was $6(3+3)$ in 1 patient (well-differentiated adenocarcinoma), and in remaining 2 patients Gleason score was $7(3+4)$, moderate differentiate adenocarcinoma. There was no mortality seen in our study. All these three patients underwent further diagnostic workup include TRUS guided biopsy and additional radiological staging investigations. They properly characterized by Damico Risk Stratification system and further treatment advised.

The clinical presentation of patients, grades of enlargements on DRE and IPSS however, demonstrated no correlation. 


\section{PRESENTATION OF PATIENTS}

\begin{tabular}{|l|c|}
\hline \multicolumn{1}{|c|}{ Presentation of Patients } & $\begin{array}{c}\text { N=No of Patients } \\
\% \text { Percentage }\end{array}$ \\
\hline Age & $\mathrm{N}=65(65 \%)$ \\
\hline $60-70$ Years & $\mathrm{N}=21(21 \%)$ \\
\hline $71-80$ Years & $\mathrm{N}=14(14 \%)$ \\
\hline$>80$ Years & 1.38 7.19 \\
\hline Mean \pm SD & $\mathrm{N}=58(58 \%)$ \\
\hline Way of Presentation & $\mathrm{N}=37(37 \%)$ \\
\hline LUTS & $\mathrm{N}=3(3 \%)$ \\
\hline Refractory retention & $\mathrm{N}=2(2 \%)$ \\
\hline LUTS with hematuria & \\
\hline LUTS with inguinal swelling & $(65 \%)$ \\
\hline Types of LUTS & $(52 \%)$ \\
\hline Increased frequency of Micturition & $(70 \%)$ \\
\hline Urgency & $(64 \%)$ \\
\hline Nocturia & $(56 \%)$ \\
\hline Straining & $(44 \%)$ \\
\hline Weak stream & $(39 \%)$ \\
\hline Intermittency & $\mathrm{N}=39(39 \%)$ \\
\hline Incomplete emptying & $\mathrm{N}=16(16 \%)$ \\
\hline IPSS & $\mathrm{N}=8(8 \%)$ \\
\hline $20-25 / 35$ & $\mathrm{~N}=27(27 \%)$ \\
\hline $26-30 / 35$ & $\mathrm{~N}=36(36 \%)$ \\
\hline $31-35 / 35$ & $\mathrm{~N}=37(37 \%)$ \\
\hline DRE & \\
\hline Grade I enlargement & \\
\hline Grade II enlargement & \\
\hline Grade III enlargement & \\
\hline & \\
\hline
\end{tabular}

\section{ANALYSIS AFTER TUPR}

\begin{tabular}{|l|c|}
\hline Biopsy Report & \\
\hline Benign prostatic hyperplasia & $\mathrm{N}=97(97 \%)$ \\
\hline Prostatic carcinoma & $\mathrm{N}=3(3 \%)$ \\
\hline PSA Values & \\
\hline Less than $10 \mathrm{ng} / \mathrm{ml}$ & $\mathrm{N}=1(01 \%)$ \\
\hline More than $10 \mathrm{ng} / \mathrm{ml}$ & $\mathrm{N}=2(02 \%)$ \\
\hline
\end{tabular}

\section{DISSCUSION}

Prostate cancer remains the second most commonly diagnosed cancer in men, with an estimated 1.1 million diagnoses worldwide in 2012 , accounting for $15 \%$ of all cancers diagnosed ${ }^{10}$, in which Prostatic adenocarcinoma accounts for $95 \%$ of all prostatic neoplasms which arises from the peripheral zone of the prostate.

Incidental Prostatic carcinoma (IPCa) is defined as a "cancer which lacks apparent neoplastic symptoms or cancer which is unusually detected by microscopic examination of resected tissue that had been previously diagnosed as benign. ${ }^{11}$ Different screening programs in the past have led to detection of prostate carcinoma but, With the use of traditional and latest modern screening methods and techniques for PAC, including digital rectal examination (DRE), measurement of prostate-specific antigen (PSA), and transrectal ultrasound (TURS) and prostate biopsy, have not only reported better diagnosis of PAC but also an increase in the incidence of PAC. ${ }^{12}$ Today, $\mathrm{PCa}$ is more frequently being diagnosed in asymptomatic patients with localized disease. Owing to early diagnosis, more cases of focal PCa or IPCa are diagnosed. ${ }^{13}$

The European Union of Urology's guidelines defines the incidental Tumour as T1a and T1b. According to this classification 'Tumour Node Metastasis (TNM) classification of prostatic cancer', the Clinical T1 or incidental prostate cancer is defined as "the clinically inapparent tumour that is neither palpable nor visible by imaging". Clinical T1a and T1b prostate cancer are diagnosed at the time of transurethral resection of the prostate (TURP) for benign prostatic disease. T1a disease involves $5 \%$ or less of the resected tissue, whereas $\mathrm{T} 1 \mathrm{~b}$ disease involves more than $5 \%$ of the resected tissue. ${ }^{14}$

Transurethral resection of the prostate (TURP) targets the transitional zone of the prostate, Prostate cancer isolated exclusively in the transitional zone (TZ) is uncommon, accounting for only $2-7 \%$ of all prostate cancers. ${ }^{15}$ Several recent studies have reported that cancer arising from the TZ have a more favorable prognosis than tumors that arise in the peripheral zone (PZ). ${ }^{16}$

In men the Prostatic cancer appears as significant health problem, its incidence is age dependent. Studies showed a prevalence of $\mathrm{PCa}$ at age < 30 years of $5 \%(95 \% \mathrm{Cl}: 3-8 \%)$, increasing by an odds ratio of $1.7(1.6-1.8)$ per decade, to a prevalence of $59 \%$ (48-71\%) by age $>79$ years. ${ }^{17}$ In our study the most commonly 71 years of age was affected. BPH is one of the most common manifestations in older individuals as evident from literature. It accounts for $70 \%$ of men over 70 
years of age. Our study showed nearly consistent finding. In our study, however, the patients with biopsy-proven prostate carcinoma the mean age were 69yrs. Brandon Otto et al conducted study on 793 men to find the pathology of prostate, all were between 45-90 years of age and the median age was 71 years. In their study $98.6 \%$ were diagnosed as benign prostatic hyperplasia or inflammation on pathology and $1.4 \%$ was found to have prostatic cancer on pathology. ${ }^{18}$ Saman $S \mathrm{~T}$ et al performed study on 1250 patients to evaluate the prostatic disease and the mean age was 71.1 years in their study. Due to awareness of disease of prostate by various health programs, seminars, handouts, and increasing quality of treatment modalities for the patients of prostatic enlargement and increasing life expectancy, the most common specimen received by the pathologist for analysis to diagnose benign / malignant disease. ${ }^{19}$

In our study, 100 TURP specimens were analyzed by the histopathologist to find out the incidence of a prostatic tumour in clinically benign prostatic disease (clinical T1a or T1b) and we found that 3 patients out of 100 (3\%) showed Prostatic cancer in TURP specimen. A large retrospective study conducted by Brandon Otto et al in recent past, evaluated the TURP specimens of 771 patients and they had concluded that the incidence of prostatic cancer in their study was $1.4 \%(\mathrm{~N}=11)$, and the reason of this lower incidence in this study was the exclusion of all those cases who were PSA positive (elevation) or suspicious DRE. ${ }^{18}$ Saman ST et al in their study of 1250 patients found 95.36 $\%$ of the specimen showed Benign pathology and $4.64 \%$ of cases with histopathology favoured prostatic cancer. ${ }^{19}$ Christopher Barbieri et al in their study of 548 (98.9\%) patients demonstrated benign pathology with no evidence of carcinoma and Six $(1.1 \%)$ patients were incidentally found to have prostate cancer on resected tissue pathology. All were found to have the low grade and low volume disease..$^{20}$ On the other hand, the growing awareness and use of medical management of benign prostatic disease and use of Laser In prostatic surgery in which the prostatic tissue will not be available, are the other reasons of lower incidence of Prostatic cancer in TURP specimen.

Before the PSA screening/essay the incidental prostatic cancer rate was $27 \%$ at the time of TURP. ${ }^{21}$ With an increase in PSA screening, there has been a decrease in pT1a and pT1b lesions (4.4\% to $2.2 \%$ and $10.5 \%$ to $2.8 \%$, resp. Jones et al.'s comparison found a decrease of incidental prostate cancer from $14.9 \%$ to $5.2 \%$ (pre versus post PSA era) in over 700 patients $^{22}$, the other interesting thing is that several advanced prostatic cancers had PSA level in the usual normal range thus limit the usefulness of PSA screening to some extent.

A multicenter review by Yoo et al. showed an incidental prostate cancer rate of $4.8 \%$ in over 1600 patients. They found that in addition to DRE findings, the combination of transitional zone volume and PSA could be useful predictors of incidental prostate cancer. ${ }^{23}$

In our study, only 3 patients were diagnosed with a case of adenocarcinoma of the prostate on histopathology. Maximum numbers of our cases were in the 7th decade, then we advised their PSA, which was done after one month of TURP to rule out the false positive result. We found that their PSA was elevated. Out of three, one PSA value was below 10 and the remaining two had value more than 10. In our study prostatic adenocarcinoma with Gleason's score $6(3+3)$ was found in 1 case and Gleason scores $7(3+4)$ was found in 2 cases. All these three patients underwent further diagnostic workup include TRUS guided biopsy and additional radiological staging investigations. They properly characterized by Damico Risk Stratification system and treatment advised.

The clinical implication of this study is to emphasize the importance of evaluation of biopsy specimen especially in those patients who have positive family history of prostatic cancer and also to prefer conventional TURP over laser TURP/ Ablation to obtain tissue diagnosis.

Despite intensive research over the last several decades, many questions particularly those concerning early diagnosis and the choice of 
optimal treatment for each individual patient, still remain unanswered.

\section{CONCLUSION}

$\mathrm{BPH}$ is more common between 60-80yrs. When patient undergo TURP or open prostatectomy, every specimen should be sent for biopsy because prostate cancer is only confirmed by biopsy, so that prostate cancer is detected early. Radiology \& PSA values are supportive in their role but are not true diagnostic. Prostatic cancer is a significant morbid condition, so effective measures should be taken to detect prostatic cancer, so that patient can be properly treated according to the stage.

\section{CONFLICT OF INTERESTS}

The authors declare that there is no conflict of interest regarding the publication of this paper. Copyright@ 15 Dec, 2018.

\section{REFERENCES}

1. Chou R, Dana T, Bougatsos C, et al. Treatments for Localized Prostate Cancer: Systematic Review to Update the 2002 U.S. Preventive Services Task Force Recommendation [Internet]. Rockville (MD): Agency for Healthcare Research and Quality (US); 2011 Oct. (Evidence Syntheses, No. 91.) Available from: https:// www.ncbi.nlm.nih.gov/books/NBK82315/

2. Wehrberger $\mathrm{C}$, Madersbacher $\mathrm{S}$, Jungwirth $\mathrm{S}$, Fischer $\mathrm{P}$, Tragl $\mathrm{KH}$. Lower urinary tract symptoms and urinary incontinence in a geriatric cohort - a populationbased analysis. BJU Int. 2012 Nov; 110(10):1516-21. doi: 10.1111/j.1464-410X.2012.11022.x. Epub 2012 Mar 12.

3. Abrams P. New words for old-lower urinary tract symptoms for proststism; BMJ 1994; 308:929-30. doi: https://doi.org/10.1136/ bmj.308.6934.929 (Published 09 April 1994).

4. Lower urinary tract symptoms in men: Management (CG97). Evidence-based recommendations on managing lower urinary tract symptoms (LUTS) in men. NICE Clinical Guideline (May 2010). https://www. nice.org.uk/guidance/cg 97.

5. Daniels NA', Ewing SK, Zmuda JM, Wilt TJ, Bauer DC; Osteoporotic Fractures in Men (MrOS) Research Group. Correlates and prevalence of prostatitis in a large community-based cohort of older men. Urology, 2005; 66(5):964-970. https://www.ncbi.nlm.nih.gov/ pubmed/16286104.
6. Donald J. Tindall, Roger S. Rittmaster. The Rationale for inhibiting 5a-reductase isoenzymes in the prevention and treatment of prostate cancer. J Urol, $2008 \mathrm{Apr}$; 179(4):1235-1242. doi: 10.1016/j.juro.2007.11.033.

7. McDougal WS, Wein AJ, Kavoussi LR, Partin AW, Peters CA. Campbell-Walsh Urology 11th Edition Review E-Book. Elsevier Health Sciences; 2015 Sep 25.

8. Beerlage HP, Van Leenders GJ, Oosterhof GO, Witjes JA, Ruijter ET, Van de Kaa CA, Debruyne FM, De la Rosette JJ. High-intensity focused ultrasound (HIFU) followed after one to two weeks by Radical Retropubic Prostatectomy: Results of a prospective study. Prostate. 1999 Apr 1; 39(1):41-6. https://www. ncbi.nlm.nih.gov/pubmed/10221265.

9. Lodh B, Sinam RS, Singh KA. Digital rectal grading of benign prostatic hyperplasia: Where does it stand today?. J Mahatma Gandhi Inst Med Sci 2016; 21:40-5.

10. Ferlay, J., Soerjomataram I, Dikshit R, Eser S, Mathers C, Rebelo M, Parkin DM, Forman D, Bray F. Cancer incidence and mortality worldwide: Sources, methods and major patterns in Globocan 2012. Int J Cancer. 2015 Mar 1; 136(5):E359-86. doi: 10.1002/ ijc.29210.

11. Napal Lecumberri S, Lameiro Couso FJ, Rubio Navarro C, Gómez Dorronsoro M, Larrínaga Liñero B, Ipiéns Aznar A. Estudio de la progresión del cáncer de próstata incidental según el tipo de tratamiento aplicado [A study of the progression of the incidental prostate cancer depending on the kind of treatment performed]. Actas Urol Esp. 2007; 31(8):810-18. Spanish.

12. Anwar F, Mohayuddin QN, Islam M, Aasim M, Riaz M, Khan $A$. Cancer in patients undergoing trans urethral resection of prostate (TURP) for clinically benign symptomatic enlarged prostate. J Postgrad Med Inst 2012; 26(4): 428-31.

13. Abedi A, Fallah-Karkan M, Allameh $F$, Ranjbar A, Shadmehr A. Incidental prostate cancer: A 10-year review of a tertiary center, Tehran, Iran. Research and reports in urology. 2018; 10:1-6. doi:10.2147/RRU. S146159.

14. N. Mottet, J. Bellmunt, E. Briers, M. Bolla, P. Cornford, M. De Santis, A. Henry, S. Joniau, T. Lam, M.D. Mason, V. Matveev, H. van der Poel, et al. EAU - ESTRO - ESUR -SIOG Guidelines on Prostate Cancer. Epidemiology and Aetiology. European Association of Urology 2017: Prostate cancer - update March 2017:12.

15. Andreas Erbersdobler, Herbert Augustin, Thorsten Schlomm, Rolf $\square$ Peter Henke. Prostate cancers in the transition zone: Part 1; pathological aspects. BJU Int. 2004; 94(9):1221-25. 
16. Perera M, Lawrentschuk N, Perera N, Bolton D, Clouston D. Incidental Prostate cancer in transurethral resection of prostate specimens in men aged up to 65 years. Prostate International. 2016; 4(1):11-14. doi:10.1016/j.prnil.2015.10.016.

17. Bell KJ, Del Mar C, Wright G, Dickinson J, Glasziou P. Prevalence of incidental prostate cancer: A systematic review of autopsy studies. Int $\mathrm{J}$ Cancer. 2015 Oct 1; 137(7):1749-57. doi: 10.1002/ ijc.29538.

18. Brandon Otto, Christopher Barbieri, Richard Lee, Alexis E. Te, Steven A. Kaplan, Brian Robinson, Bilal Chughtai. Incidental prostate cancer in transurethral resection of the prostate specimens in the modern Era. Advances in Urology, vol. 2014, Article ID 627290, 4 pages, 2014. https://doi.org/10.1155/2014/627290.

19. Saman S, Talab, Steven Lee Chang, Chin-Lee Wu, Shahin Tabatabaei. PD21-08 Incidence of prostatic adenocarcinoma in transurethral resection of the prostate (Turp) specimens in the PSA screening era. The Journal of Urology, April 2014 ; 191(4):608-9.
20. Christopher Barbieri Bilal Chughtai, Alexis E. Te, Steven A. Kaplan, Brian Robinson, Richard Lee. 2018 Incidental prostate cancer in transurethral resection of the prostate (turp) in the modern Era. The Journal of Urology, April 2012; 187(4):814-815. DOI: https://doi. org/10.1016/j.juro.2012.02.2181.

21. Tombal B, De Visccher L, Cosyns JP, Lorge F, Opsomer $R$, Wese FX, Van Cangh PJ. Assessing the risk of unsuspected prostate cancer in patients with benign prostatic hypertrophy, a 13-year retrospective study of the incidence and natural history of T1a-T1b Prostate cancers. BJU Int. 1999 Dec; 84(9):1015-20.

22. Jones JS, Follis HW, Johnson JR. Probability of finding T1a and T1b (incidental) prostate cancer during TURP has decreased in the PSA era. Prostate Cancer Prostatic Dis. 2009; 12(1):57-60. doi: 10.1038/ pcan.2008.14.

23. Yoo C, Oh CY, Kim SJ, et al. Preoperative Clinical Factors for Diagnosis of Incidental Prostate Cancer in the Era of Tissue-Ablative Surgery for Benign Prostatic Hyperplasia: A Korean Multi-Center Review. Korean Journal of Urology. 2012; 53(6):391-5. doi:10.4111/kju.2012.53.6.391.

\begin{tabular}{|c|c|c|c|}
\hline \multicolumn{4}{|c|}{ AUTHORSHIP AND CONTRIBUTION DECLARATION } \\
\hline Sr. \# & Author-s Full Name & Contribution to the paper & Author $=\mathbf{s}$ Signature \\
\hline $\begin{array}{l}2 \\
3\end{array}$ & $\begin{array}{l}\text { Salman Manzoor Qureshi } \\
\text { Muhammad Ali Sohail } \\
\text { Mujeeb ur Rehman Sahito } \\
\text { Aijaz Hussain Memon }\end{array}$ & $\begin{array}{l}\text { Data collection, write up, } \\
\text { data analysis. } \\
\text { Assisted in collecting and } \\
\text { analysis of data. } \\
\text { Assisted in literature review \& } \\
\text { statistical analysis. } \\
\text { Assisted in statistical analysis }\end{array}$ & \\
\hline
\end{tabular}

